\section{Evaluating early selection in perennial tropical forages}

\author{
Ulisses José de Figueiredoㅁ, Yasmin Vasques Berchembrock², \\ Cacilda Borges do Valle ${ }^{3}$, Sanzio Carvalho Lima Barrios ${ }^{3}$, \\ Kenneth H. Quesenberry ${ }^{4}$, Patrício Ricardo Muñoz ${ }^{5}$ and José \\ Airton Rodrigues Nunes ${ }^{2 *}$
}

\begin{abstract}
Perennial grass hybrids of Urochloa are evaluated for at least two years during the screening stage trials (SS) and advanced trials (AD) in breeding programs, an expensive and time-consuming process. In this study, we aimed to evaluate the potential for early selection of cultivars in this breeding scheme. We used multiple measurements of agronomic and nutritive value traits of Urochloa humidicola and Urochloa decumbens in the SS, and Urochloa ssp. in the AD. Repeatability coefficient, genetic correlation, selection efficiency (SE), and Spearman correlations were estimated. The results indicated that reliable early selection could be applied, decreasing the evaluation period to one year and a half for SS, and to one year for $A D$. These results were confirmed by high genetic and rank correlations, and overall SE above $50 \%$. This proposed change in the breeding scheme could save considerable time, labor, and resources and accelerate the release of improved cultivars.
\end{abstract}

Keywords: Urochloa spp., repeatability coefficient, forage breeding, rank correlation.

\section{INTRODUCTION}

The Brazilian livestock business is based on extensive grazing areas with predominance of various Urochloa species [U. brizantha (syn. Brachiaria brizantha), U. decumbens (syn. Brachiaria decumbens), U. ruziziensis (syn. Brachiaria ruziziensis), and U. humidicola (syn. Brachiaria humidicola)] and Megathyrsus maximus (syn. Panicum maximum) pastures. More than $60 \%$ of the pasture area is covered by a few Urochloa cultivars, due to their high adaptation to poor, acidic soils and the satisfactory performance of cattle grazing these Urochloa pastures (Jank et al. 2011, Nogueira 2012).

The Urochloa breeding program in Brazil began in decade 1980 at the Embrapa Beef Cattle Research Center in Campo Grande, Mato Grosso do Sul, Brazil (Valle et al. 2009, Jank et al. 2011) Research first focused on evaluation of a large collection of introduced germplasm. Exploratory crosses followed, and recurrent selection strategies have recently been used, together with crosses of superior apomictic plants as males with superior sexual females (Jank et al. 2014).

The early stage of the Embrapa's forage breeding programs has produced over 1000 individual hybrids that need to be individually evaluated under
Crop Breeding and Applied Biotechnology 19:3, 291-299, 2019 Brazilian Society of Plant Breeding. Printed in Brazil http://dx.doi.org/10.1590/198470332019v19n3a41 


\section{UJ Figueiredo et al.}

cutting in Stage I trials (Screening Stage trials). In SS, the best hybrids (100-200) are evaluated for multiple traits in small replicated plots for at least two years with multiple hand harvests per year, making it time, labor, and cost intensive. Only 20-25 genotypes are then selected for evaluation in Stage II (Advanced trials), which involves another two years and two or more locations considering the biome(s) for which the cultivar will be released. In Stage II, these small plots are harvested and evaluated for dry matter yield, regrowth, and forage nutritive value. In the last stage (Stage III or final trials), one to four genotypes selected from Stage II are evaluated for animal performance under grazing for another two years in the biome(s) under consideration. Parallel trials are carried out to screen for pest and disease resistance, response to fertilizers, and response to abiotic stresses, such as drought, water logging, toxic aluminum, etc. The forage evaluation process requires further grazing trials for cultivar release (Alves et al. 2014, Jank et al. 2014). Altogether, the selection process takes between 10 to 12 years before a cultivar is ready to be released.

The frequent concern of forage breeders is the number of harvests needed to select superior genotypes with a satisfactory level of confidence while conserving resources. Earlier selection could significantly reduce the minimum time needed to release a cultivar, but there is the concern of making a wrong decision in identification of superior genotypes with fewer harvests. The repeatability coefficient $(\rho)$ represents the upper limit of heritability, and, therefore, it indicates the efficiency of predicting genotypic value from successive measurements on an individual. Thus, $\rho$ can be used as a parameter for determining when selection can be made with confidence (Resende 2002). Studies applying $\rho$ for tropical forages report 7-8 harvests are needed for plant height and dry matter weight estimates. However, 10-14 harvests for fresh matter weight and percentage of dry matter were required to achieve coefficients of determination greater than $80 \%$ when evaluating $U$. ruziziensis half-sib progenies (Souza Sobrinho et al. 2010).

The objectives of this study were to estimate repeatability coefficients and genetic correlations from several Urochloa spp. trials in order to determine the optimal number of harvests needed for selection of genotypes for a given level of statistical confidence. The final goal is to eventually include early selection in the evaluation and breeding of perennial forages.

\section{MATERIAL AND METHODS}

\section{Site}

The field experiments were conducted in two locations, Campo Grande and Terenos, Mato Grosso do Sul, Brazil. In Campo Grande, the experiment was conducted at Embrapa Gado de Corte (lat 20 27'00" S, long 54 37' 00" W, alt $530 \mathrm{~m}$ asl), and in Terenos, the evaluation was at the Hisaeda Farm (lat $20^{\circ} 26^{\prime} 00^{\prime \prime} \mathrm{S}$, long $54^{\circ} 51^{\prime} 00^{\prime \prime} \mathrm{W}$, alt $434 \mathrm{~m}$ asl). According to the Köppen classification (Kottek et al. 2006), the climate in both locations is tropical rainy, subtype AW, characterized by a well-defined dry season in winter and a rainy season in summer.

\section{Screening stage trials (SS)}

All the SS were conducted in Campo Grande. Trial 1 (T1) consisted of 50 hybrids of $U$. humidicola and the two hexaploid parents. The cultivar BRS Tupi was used as a male parent and the sexual ecotype as the female parent. The experiment was set up in January 2007 from vegetative cuttings in a randomized complete block design (RCBD) with eight replications in $2.5 \mathrm{~m}^{2}$ plots. The plots were harvested nine times over a period of two years. Seven harvests occurred in the rainy season (27 Nov 2007; 21 Jan, 25 Feb, 8 Oct, and 9 Dec 2008; and 28 Jan and 2 Apr 2009), and two in the dry season (23 Apr 2008 and 12 Jul 2010).

Trial 2 (T2) consisted of 50 hybrids of $U$. decumbens resulting from a cross of the cultivar "Basilisk" (Oram 1990) as the male parent with three artificial tetraploid plants as sexual females. The four parents were also included as controls. The experiment was set up as a RCBD with four replications, and plots of $4.0 \mathrm{~m}^{2}$ were established using vegetative cuttings in December of 2010. Evaluations began in July 2011 for six harvests: two in the dry season (20 July 2011 and 28 Sep 2011) and four in the rainy season (4 Nov 2011, 9 Dec 2011, 18 Jan 2012, and 28 Feb 2012).

A third experiment, designated Trial 3 (T3), consisted of 324 hybrids of $U$. decumbens laid out in an $18 \times 18$ simple lattice design with a plot size of $4.0 \mathrm{~m}^{2}$. The harvests of this trial began in July 2012, and seven harvests were completed in one year: 6 July 2012 and 2 Oct 2012 (dry season); and 5 Nov 2012, 11 Dec 2012, 17 Jan 2013, and 13 Mar 2013 (rainy season). 


\section{Advanced trials (AD)}

For AD, only selected genotypes from SS were included in the evaluations. Eight genotypes [2 ecotypes (U. brizantha, B4 and B6), 2 hybrids (U. brizantha $\times$ U. ruziziensis, HBGC336 and HBGC331), and 4 commercial cultivars (U. brizantha, cv. Marandu, cv. Xaráes, and cv. BRS Piatã, and the interspecific hybrid U. brizantha $\times U$. decumbens $\times U$. ruziziensis, cv. Mulato II)] were evaluated in the two locations, Campo Grande and Terenos. In both trials, experiments were established in a RCBD with four replications in January 2009. Each $15-\mathrm{m}^{2}$ plot was sown in six 4-meter rows with $0.5 \mathrm{~m}$ spacing between rows. At each harvest, only the central $4.0 \mathrm{~m}^{2}$ were harvested, leaving a 1.0-m border on each of the four sides.

In both locations, plots were cut to stubble height to promote growth in April 2009, and dry matter was not recorded. After that, 16 harvests were completed at each location over a two-year period. These experiments are identified as Trial 4 (T4) in Campo Grande and Trial 5 (T5) in Terenos, and the evaluation of these two experiments together is Trial 6 (T6).

\section{Traits measured}

Fresh weight yield for each harvest was determined for each plot, and a subsample ( $300 \mathrm{~g}$ of fresh matter) was used for morphological separation into leaf, stem, and dead matter. Samples were then dried at $65{ }^{\circ} \mathrm{C}$ to calculate dry matter percentage (DM) for each component. Then total dry matter yield (TDM, $\mathrm{kg} \mathrm{ha}^{-1}$ ), leaf percentage (\%L), and leaf dry matter yield (LDM, kg ha-1) were estimated. Seven days after harvests, plots were visually evaluated for regrowth capacity (REG), based on the combination of density score (1: less than $20 \%$ of regrown tillers, 2: $20 \%-40 \%, 3: 40 \%$ - 60\%, 4: 60 - 80\%, and 5: more than $80 \%$ ) and rate of tiller regrowth (slow, medium, and fast growth of tiller height), following the method described in Basso et al. (2009).

For forage nutritive value, dried and ground leaf samples from all trials were used, except for T3, for which forage nutritive value data were not obtained. Crude protein (CP), neutral detergent fiber (NDF), in vitro organic matter digestibility (IVOMD), and lignin (LIG) were estimated using near infrared spectroscopy (NIRS) on a dry matter basis (Marten et al. 1989). The NIRS was previously calibrated by comparing the results obtained in the wet chemical analyses and the spectrum read from these same samples in the NIRS for several nutritional traits. Thus, a regression equation was estimated for each nutritional trait, using a set of samples of tropical forage grasses (Urochloa spp. and Megathyrsus maximus) for that purpose ( 647 samples for CP, 613 for IVOMD, 631 for NDF, and 147 for LIG). Estimates of the coefficient of determination were 0.99 (CP), 0.96 (IVOMD), 0.95 (NDF), and 0.96 (LIG), showing good fit of the model for prediction of nutritional traits (data not shown).

\section{Data analysis}

Data analysis was carried out in the software ASReml v 3.0 (Gilmour et al. 2009). For T1, T2, T3, T4, and T5, the following mixed model was used:

$$
y=X m+D b+Z g+W p+T i+e,
$$

where $y$ is the data vector; $m$ is the vector of the combined fixed effects of harvest-replication; and $b$ is the vector of random sub-block effects, where $b \sim N M V\left(0, I \sigma_{b}^{2}\right)$ and $\sigma_{b}^{2}$ is the sub-block variance (this effect was considered only for T3); $g$ is the vector of random genotypic effects, where $g \sim N M V\left(0, / \sigma_{g}^{2}\right)$ and $\sigma_{g}^{2}$ is the genotypic variance; $p$ is the vector of random permanent environmental effects or plots, where $p \sim N M V\left(0, / \sigma_{p}^{2}\right)$ and $\sigma_{p}^{2}$ is the variance associated with the plot effects; $i$ is the vector of random genotype $\mathrm{x}$ harvest interaction effects, where $i \sim N M V\left(0, l \sigma_{i}^{2}\right)$ and $\sigma_{i}^{2}$ is the variance associated with the effects of the genotype $x$ harvest interaction; and $e$ is the vector of random errors, where $e \sim N M V\left(0, / \sigma_{e}^{2}\right)$ and $\sigma_{e}^{2}$ is the error variance. $X, D, Z, W$, and $T$ are the incidence matrices of the effects $m, b, g$, $p$, and $i$, respectively.

For T6, we used the following mixed model:

$$
y=X m+Z g+S p+T g h+Q g l+W g h l+e,
$$

where $y$ is the data vector; $m$ is the vector of the combined fixed effect of harvest-replication-location; $g$ is the vector of random genotypic effect, where $g \sim N M V\left(0, l \sigma_{g}^{2}\right)$ and $\sigma_{g}^{2}$ is the genotypic variance; $p$ is the vector of random permanent environmental effect or plots, where $p \sim N M V\left(0, l \sigma_{p}^{2}\right)$ and $\sigma_{p}^{2}$ is the variance of plot effects; $g h$ is the vector 


\section{UJ Figueiredo et al.}

of the random genotype $x$ harvest interaction effect, where $g h \sim N M V\left(0, l \sigma_{g h}^{2}\right)$ and $\sigma_{g h}^{2}$ is the variance associated with the effects of the genotype $x$ harvest interaction; $g l$ is the vector of the random genotype $x$ location interaction effect, where $g l \sim N M V\left(0, l \sigma_{g l}^{2}\right)$ and $\sigma_{g l}^{2}$ is the variance associated with the effects of the genotype $x$ location interaction; $g h l$ is the vector of the random genotype $x$ harvest $x$ location interaction effect, where $g h l \sim N M V\left(0, l \sigma_{g h l}^{2}\right)$ and $\sigma_{g h l}^{2}$ is the variance associated with the effects of the genotype $\mathrm{x}$ harvest $\mathrm{x}$ location interaction; and $e$ is the vector of random errors, where $e \sim N M V\left(0, l \sigma_{e}^{2}\right)$ and $\sigma_{e}^{2}$ is the error variance. $X, Z, S, T, Q$, and $W$ are incidence matrices of the random effects $m, g, p, g h, g l$, and $g h l$, respectively.

The normality assumption of errors was checked by the normal quantile-quantile (QQ) plot, and according to the diagnostic plot, the approximation was adequate (Kosak and Piepho 2017). The significance of the variance components was verified by the likelihood ratio test (LRT) (Resende 2002). The precision of the genetic predictions was based on the accuracy $\left(\hat{r}_{\tilde{g} g}\right)$ computed by the following estimator: $\hat{r}_{\tilde{g} g}=\left(1-\mathrm{PEV} / \hat{\sigma}_{g}^{2}\right)^{1 / 2}$, in which PEV is the prediction error variance (Resende and Duarte 2007).

For each trial, the analysis of accumulated harvest was fitted for the first two harvests and then additional harvests were added sequentially in different analyses until all harvests in each trial were considered in the analysis. That way we could define the optimal number of harvests needed to make the selection with high reliability. The repeatability coefficient $(\rho)$ was estimated from the variance components by the following expressions (Falconer and Mackay 1996):

$\rho=\frac{\sigma_{g}^{2}+\sigma_{p}^{2}}{\sigma_{g}^{2}+\sigma_{g}^{2}+\sigma_{g / r k}^{2}+\sigma_{e}^{2} / r k}$

for $\mathrm{T} 1, \mathrm{~T} 2, \mathrm{~T} 3, \mathrm{~T} 4$ and $\mathrm{T} 5$,

$\rho=\frac{\sigma_{g}^{2}+\sigma_{p}^{2}}{\sigma_{g}^{2}+\sigma_{g}^{2}+\sigma_{g h / k}^{2}+\sigma_{g l / k l}^{2}+\sigma_{e / r k l}^{2}}$

for T6,

where $k, l$, and $r$ are the number of harvests, locations, and replications, respectively.

Additionally, the genetic correlation $\left(r_{\text {gij }}\right)$ between the mean of the optimal number of harvests $i$ and the mean of all harvests $j$ was estimated from a bivariate mixed model for each trait using the expression $r_{i j}=\sigma_{g i j} \times\left(\sigma_{g i}^{2} \times \sigma_{g j}^{2}\right)^{-1 / 2}$, where $\sigma_{g i j}$ is the genetic covariance between the mean of the optimal number of harvests $i$ and the mean of all harvests $j ; \sigma$ ${ }_{g i}^{2}$ is the genetic variance associated with the mean of the optimal number of harvests $i$; and $\sigma_{g j}^{2}$ is the genetic variance associated with the mean of all harvests $j$. Whenever the standard error of the genetic correlation was at least $50 \%$ below the estimate (statistic $t \cong 2$ ), it was considered significant $(P<0.05)$. The bivariate mixed model was adjusted in a similar way to the univariate approach as follows:

$y_{1}=X_{1} m_{1}+D_{1} b_{1}+Z_{1} g_{1}+e_{1}$, for the optimal number of harvests;

$y_{2}=X_{2} m_{2}+D_{2} b_{2}+Z_{2} g_{2}+e_{2}$, for the mean of all harvests;

The bivariate model in matrix notation for traits $y_{1}$ and $y_{2}$ can be written as follows:

$\left[\begin{array}{l}y_{1} \\ y_{2}\end{array}\right]=\left[\begin{array}{cc}x_{1} & 0 \\ 0 & x_{2}\end{array}\right]\left[\begin{array}{l}m_{1} \\ m_{2}\end{array}\right]+\left[\begin{array}{cc}D_{1} & 0 \\ 0 & D_{2}\end{array}\right]\left[\begin{array}{l}b_{1} \\ b_{2}\end{array}\right]+\left[\begin{array}{cc}z_{1} & 0 \\ 0 & z_{2}\end{array}\right]\left[\begin{array}{l}g_{1} \\ g_{2}\end{array}\right]+\left[\begin{array}{l}e_{1} \\ e_{2}\end{array}\right]$,

where

$\left[\begin{array}{l}b_{1} \\ b_{2}\end{array}\right] \sim N M V(0, B),\left[\begin{array}{l}g_{1} \\ g_{2}\end{array}\right] \sim N M V(0, G),\left[\begin{array}{l}e_{1} \\ e_{2}\end{array}\right] \sim N M V(0, R)$,

and

$B=I \otimes\left[\begin{array}{ll}\sigma_{b_{1}}^{2} & \sigma_{\mathrm{b}_{12}} \\ \sigma_{\mathrm{b}_{12}} & \sigma_{\mathrm{b}_{2}}\end{array}\right], G=I \otimes\left[\begin{array}{cc}\sigma_{\mathrm{g}_{1}}^{2} & \sigma_{\mathrm{g}_{12}} \\ \sigma_{\mathrm{g}_{12}} & \sigma_{\mathrm{g}_{2}}^{2}\end{array}\right]$, and $R=I \otimes\left[\begin{array}{cc}\sigma_{\mathrm{e}_{1}}^{2} & \sigma_{\mathrm{e}_{12}} \\ \sigma_{\mathrm{e}_{12}} & \sigma_{\mathrm{e}_{2}}^{2}\end{array}\right]$,

where $\sigma_{\mathrm{b}_{12}}, \sigma_{\mathrm{g}_{12}}$, and $\sigma_{\mathrm{e}_{12}}$ are the covariance between $y_{1}$ and $y_{2}$ for blocks, genotypes, and errors, respectively; and $\otimes$ is the Kronecker product.

Selection efficiency (SE) was used to check the change in ranking of the genotypes, based on the genetic values, considering the optimal number of harvests and the total number of harvests evaluated in two years. SE was estimated 
using $\mathrm{SE}=\frac{\mathrm{A}-\mathrm{C}}{\mathrm{B}-\mathrm{C}} \times 100$ (Hamblin and Zimmermann 1986), where $A$ is the number of coincident genotypes in two selections; $B$ is the number of genotypes selected [10 (T1), 4 (T4, T5, and T6)]; and $C$ is the common number of genotypes taken at random in two selections $(C=i \times B)$, where $i$ is the intensity of selection: $20 \%$ for T1, T2, and T3 and $50 \%$ for $\mathrm{T} 4, \mathrm{~T} 5$, and T6.

\section{RESULTS AND DISCUSSION}

In evaluation of plant breeding experiments, selective accuracy is an important indicator of the reliability of selection since accuracy measures the correlation between the estimates or predictions and the actual breeding values (Resende and Duarte 2007). Thus, considering all the harvests in the SS (T1, T2, and T3), accuracy ranged from $48 \%$ (T3, CP) to 89\% (T2, \%L), whereas for AD, the magnitudes ranged from 69\% (T6, LIG) to 97\% (NDF, T4 and T6).

Genotypic variance was significant for most traits in the trials based on the LRT $(P<0.05)$, except for TDM (T4 and T6) and LIG (T6). This evidence of broad genetic variability allows the selection of genotypes for agronomic and nutritive value traits. However, the genotype $\mathrm{x}$ harvest interaction $(\mathrm{GHI})$ effect was significant $(P<0.05)$ for all traits, except for forage nutritive value traits on T1 and T6, reflecting differences in the relative performance of genotypes across harvests. Thus, GHI directly impacts the $\rho$ and the definition of how many harvests are necessary to adequately test a genotype.

For SS, the $\rho$ increased as harvests were added, especially for agronomic traits, whose values were higher than for forage nutritive value traits (Figures 1 and 2). T1 is an evaluation of $U$. humidicola, and in this case, $\rho$ increased up to a year and a half of evaluation, especially for agronomic traits, except for LIG. In addition, REG and CP $\rho$ values remained
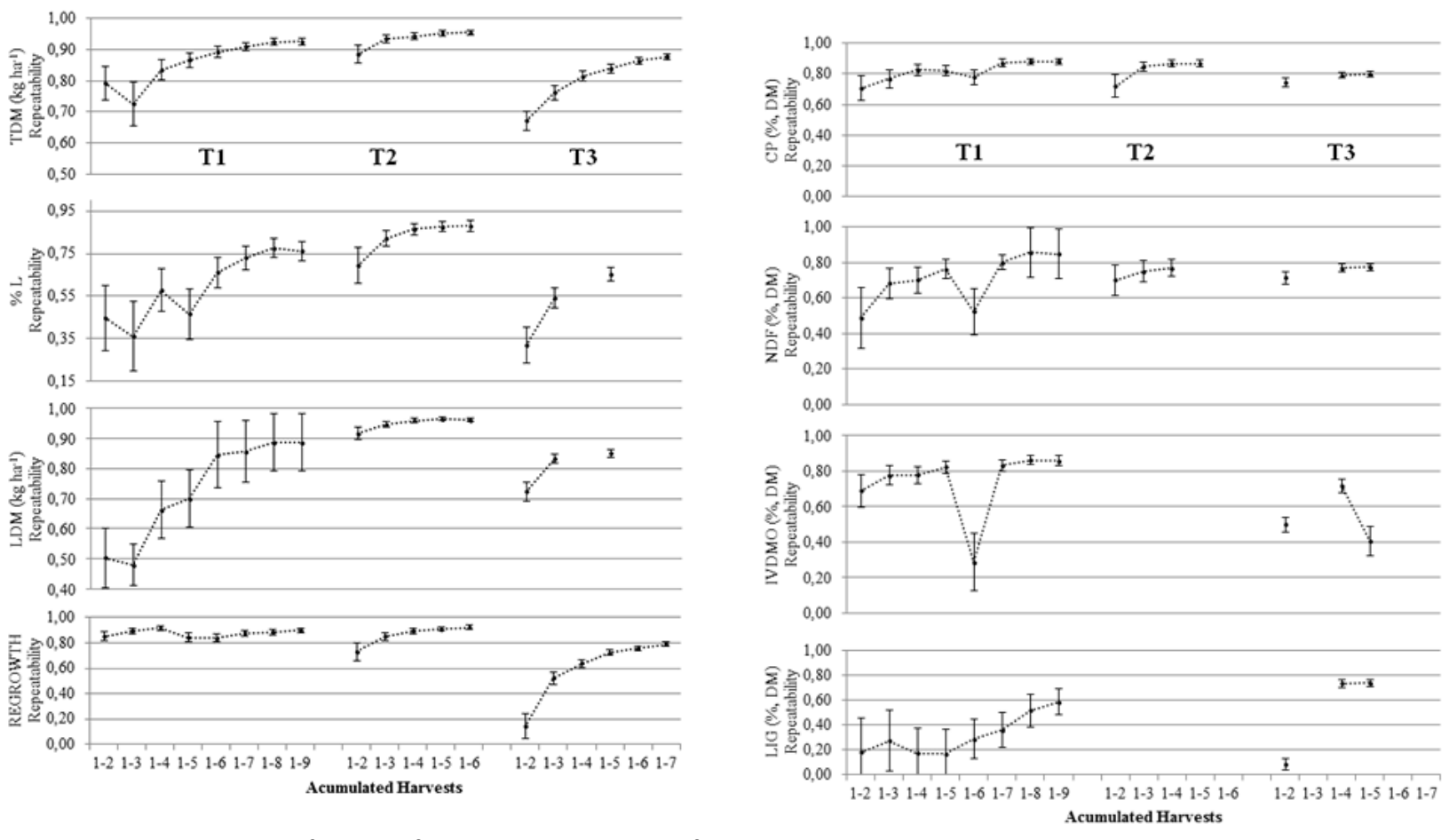

Figure 1. Repeatability coefficients of the agronomic traits of $U$. humidicola (Trial 1, T1) and U. decumbens (Trial 2, T2; Trial 3, T3) from analysis of accumulated harvests (additional harvests were added sequentially in different analyses until all harvests in each trial were considered). TDM, total dry matter yield; \%L, leaf percentage; LDM, leaf dry matter yield; REG, regrowth. Bars are standard errors for each estimate of the repeatability coefficient.

Figure 2. Repeatability coefficients of the nutritive value traits of $U$. humidicola (Trial 1, T1) and $U$. decumbens (Trial 2, T2; Trial 3, T3) from analysis of accumulated harvests. CP, crude protein; NDF, neutral detergent fiber; IVOMD, in vitro organic matter digestibility; LIG, lignin. Bars are standard errors for each estimate of the repeatability coefficient. 


\section{UJ Figueiredo et al.}

high after the first harvest. As for T2 and T3, where hybrids of $U$. decumbens were evaluated for one year, the $\rho$ values were similar to those achieved in T1. Forty-seven hybrids tested in $\mathrm{T} 2$ were tested in $\mathrm{T} 3$, and there was variability for the traits measured in both. Genetic variation in U. decumbens was also reported by Matias et al. (2016) when there were evaluated full-sib progenies for agronomic and nutritional value traits. Thus, the lower $\rho$ observed in the first harvests for T3 was probably due to the higher phenotypic variance in T3 than T2.

In Urochloa breeding programs, normally a large number of genotypes are evaluated for two years, and several traits are measured (Jank et al. 2014). Thus, considering our results for initial screening trials, the agronomic traits could be reliably evaluated in a shorter time. The $\rho$ values were above 0.80 after six accumulated harvests in T1 and T3, and after four in T2 (Figure 1). According to Resende (2002), this value of $\rho$ represents a determination coefficient above 0.89, which is recommended for selection of genotypes in breeding populations. In experiments with Megathyrsus maximus progenies, Resende et al. (2004) reported similar results, where the $\rho$ estimates were high, and their values increased less than 5\% for TDM and LDM after three years of evaluation.

The AD showed magnitudes of $\rho$ around 0.90 for almost all traits, and above 0.90 for REG (T6) (Figure 3), CP, and NDF (T4, T5, and T6) (Figure 4) after the first two harvests up to the sixteenth harvests in these trials. In contrast to the SS, the $\rho$ values were above 0.90 for TDM and LDM in trials T4 and T6, considering two to four cumulative harvests. However, after nine harvests, these estimates plateaued around 0.60, 0.70, 0.75, and 0.80 for TDM (T4 and T6) and LDM (T4 and T6), respectively. Besides for AD, standard errors had an overlap for accumulated harvests probably due to the $\rho$ values showing little change after the first accumulated harvests.

Advanced trials within this forage breeding program are conducted with the goal of testing candidate genotypes that may ultimately become cultivars. Usually, Stage II trials test less than ten genotypes, and the Brazilian Ministry of

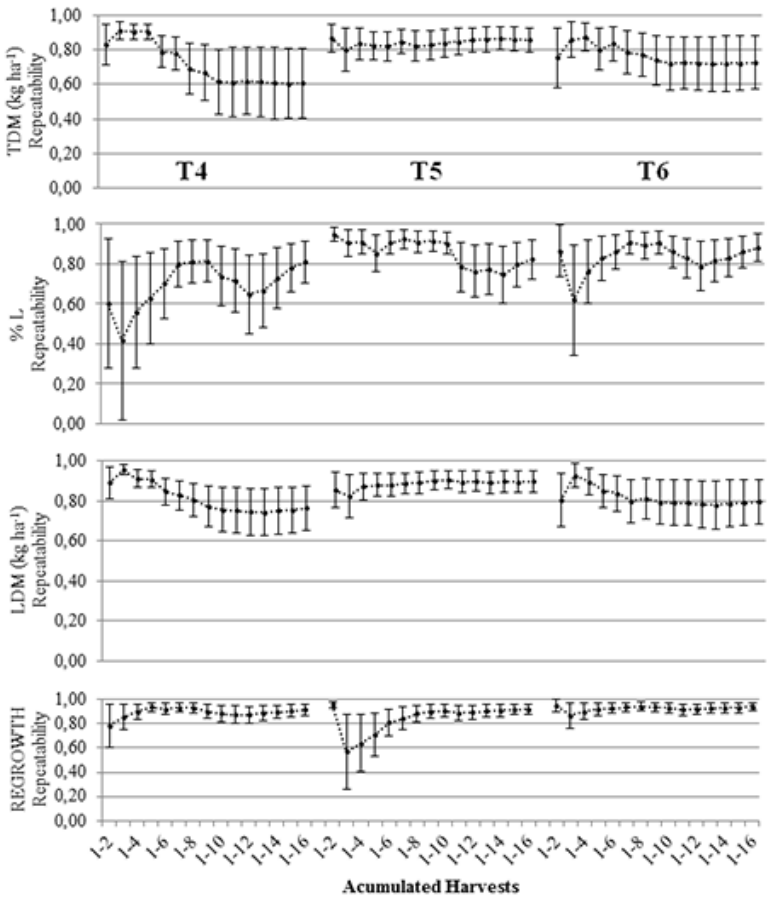

Figure 3. Repeatability coefficients of the agronomic traits of Urochloa ssp. in Trial 4 (T4), Trial 5 (T5), and Trial 6 (T6) from analysis of accumulated harvests. TDM, total dry matter yield; \%L, leaf percentage; LDM, leaf dry matter yield; REG, regrowth. Bars are standard errors for each estimate of the repeatability coefficient.

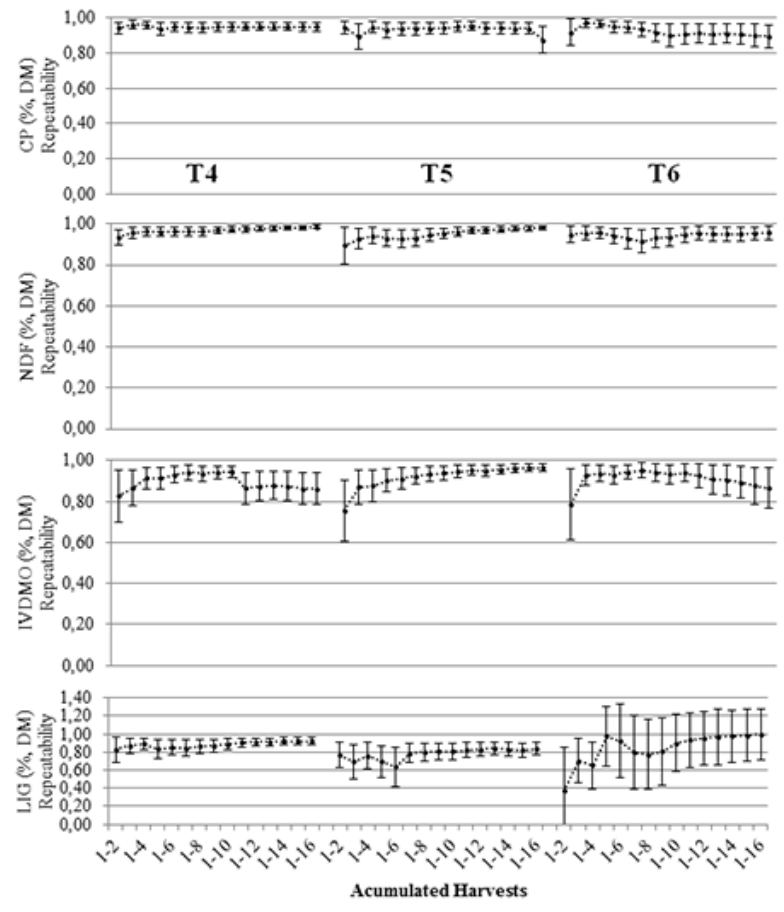

Figure 4. Repeatability coefficients of the nutritive value traits of Urochloa ssp. in Trial 4 (T4), Trial 5 (T5), and Trial 6 (T6) from analysis of accumulated harvests. $C P$, crude protein; NDF, neutral detergent fiber; IVOMD, in vitro organic matter digestibility; LIG, lignin. Bars are standard errors for each estimate of the repeatability coefficient. 
Agriculture (MAPA) requires two years of evaluation under cutting and a further two years under grazing. After these evaluations, and considering the predicted breeding values for the agronomic and nutritive value traits of the genotypes tested compared to commercial cultivars, genotypes B6 and HBGC331 were released as new cultivars. B6 was released as the cultivar BRS Paiaguás, and HBGC331 as the cultivar BRS Ipyporã.

For agronomic traits, the $\rho$ were rather variable in the early harvests but plateaued after eight accumulated harvests (Figure 3). TDM showed a lower $\rho$ value compared to the other traits in T4, but TDM showed no significant differences in the last harvests evaluated. For other traits, the plateau began in values above 0.80 after two harvests, suggesting the possibility of shorter evaluation periods that can reduce financial and time requirements.

MAPA also requests measurements of forage nutritive value traits. Our results indicate a situation more favorable than for agronomic traits, e.g., the $\rho$ for CP and NDF were above 0.90 after the first harvests evaluated, and above 0.80 for IVOMD (Figure 4). Thus, the forage nutritive value traits only need to be measured for two to three harvests, mainly for SS (Figueiredo et al. 2012). A more detailed evaluation of forage nutritive value can be addressed through pasture management trials prior to or after the release of a cultivar (Silva and Nascimento Júnior 2007). Nevertheless, it should be emphasized that environmental variation over a period of years and within years are significant determinants of nutritive value and forage yield (Euclides et al. 2009).

The purpose of this study was to predict an optimal number of harvests based on $\rho$ estimates of accumulated harvests, where if the $\rho$ is high, multiple measures are unnecessary (Pedrozo et al. 2011). For trials T4, T5, and T6, the $\rho$ reached a plateau with high magnitudes after one year of evaluation, while for $\mathrm{T} 1$, this occurred in one year and a half. Thus, to confirm if early selection is possible, genetic correlation was estimated to determine if the level of association among genotypes changed over harvests (Casler 1999). The results indicated a satisfactory correlation between this optimal number compared to the mean of all harvests (Table 1).

Our results suggest that with $U$. humidicola hybrids, the period of experimental evaluation can be reduced by at least a half year and they show that one year is sufficient for reliable selection of Urochloa ssp. genotypes for agronomic and forage nutritive value traits in advanced stages. This suggestion is based on the correlation between selection making based on selection from all harvests compared to selection from six harvests. Specifically, for forage nutritive value traits, the correlations were almost 1.0, and the number of harvests should be even fewer than for agronomic traits.

Selection efficiency (SE) was used to evaluate the behavior of selection considering the optimal number of harvests based on the $\rho$ and genetic correlation. For T1, six harvests (one year and a half) were considered, while for T4, T5, and T6, this number was eight harvests (one year). Considering screening trials (T1) for U. humidicola, SE ranged from $62.5 \%$ (IVOMD, LIG) to $87.5 \%$ (TDM, \%L, REG). Furthermore, considering ten genotypes selected from six harvests and those selected in all nine harvests, the coincidence was high, i.e., in nine genotypes (TDM, \%L, REG, NDF), eight (CP), and seven (LDM, IVOMD, LIG) (Table 2).

Table 1. Estimates of genetic correlation and their standard deviations (SD) between the mean of the optimal number of harvests and the mean of all harvests for agronomic and forage nutritive value traits of $U$. humidicola (Trial $1, T 1)$ and Urochloa ssp. (Trial 4 , T4; Trial 5, T5; and Trial 6, T6)

\begin{tabular}{|c|c|c|c|c|c|c|c|c|}
\hline \multirow{2}{*}{ Traits } & \multicolumn{2}{|c|}{ T1 } & \multicolumn{2}{|c|}{ T4 } & \multicolumn{2}{|c|}{ T5 } & \multicolumn{2}{|c|}{ T6 } \\
\hline & $r_{\overline{6}-\overline{9}}^{+t}$ & SD & $r_{\overline{8}-\overline{16}}{ }^{t+t}$ & SD & $r_{\overline{8}-\overline{16}}{ }^{t+t}$ & SD & $r_{\overline{8}-16}{ }^{t++}$ & SD \\
\hline $\mathrm{TDM}^{+}$ & 0.98 & 0.01 & 0.94 & 0.06 & 0.92 & 0.07 & 0.97 & 0.04 \\
\hline LDM & 0.99 & 0.01 & 0.96 & 0.04 & 0.93 & 0.06 & 0.96 & 0.04 \\
\hline REG & 0.99 & 0.01 & 0.97 & 0.02 & 0.92 & 0.06 & 0.95 & 0.04 \\
\hline $\mathrm{CP}$ & 0.99 & 0.01 & 1.00 & 0.45 & 0.91 & 0.07 & 0.98 & 0.03 \\
\hline IVOMD & 1.00 & 0.02 & 0.98 & 0.03 & 1.00 & 0.01 & 0.99 & 0.02 \\
\hline LIG & 1.00 & 0.06 & 0.94 & 0.05 & 0.74 & 0.23 & 0.88 & 0.12 \\
\hline
\end{tabular}

† TDM, total dry matter yield; \%L, leaf percentage; LDM, leaf dry matter yield; REG, regrowth; CP, crude protein; NDF, neutral detergent fiber; IVOMD, in vitro organic matter digestibility; LIG, lignin. †+ Genetic correlation between the six (one year and a half period) and nine (two year period) harvests for U. humidicola. $+\dagger+$ Genetic correlation between the eight (one year period) and sixteen (two year period) harvests for Urochloa ssp. 


\section{UJ Figueiredo et al.}

Table 2. Number of coincident genotypes and estimates of selection efficiency (SE) (between parentheses) and Spearman correlation $\left(r_{s}\right)$ between the optimal number of harvests and all harvests evaluated ( $\mathrm{n}$ ) of trials T1, T4, T5, and T6 for agronomic and forage nutritive value traits

\begin{tabular}{|c|c|c|c|c|c|c|c|c|}
\hline \multirow{2}{*}{ Traits } & \multicolumn{2}{|c|}{ T1 } & \multicolumn{2}{|c|}{$\mathrm{T} 4$} & \multicolumn{2}{|c|}{ T5 } & \multicolumn{2}{|c|}{ T6 } \\
\hline & n (SE \%) & $r_{s}$ & n (SE \%) & $r_{s}$ & n (SE \%) & $r_{s}$ & n (SE \%) & $r_{s}$ \\
\hline $\mathrm{TDM}^{+}$ & 9 (87.5) & $0.97 * *$ & $3(50)$ & $0.88 * *$ & $3(50)$ & $0.95^{* *}$ & $2(0)$ & $0.93 * *$ \\
\hline$\% \mathrm{~L}$ & $9(87.5)$ & $0.90 * *$ & $4(100)$ & $0.79 *$ & $3(50)$ & $0.74^{*}$ & $2(0)$ & $0.71^{*}$ \\
\hline LDM & 7 (62.5) & $0.97 * *$ & $4(100)$ & $0.76^{*}$ & $4(100)$ & $0.83 * *$ & $2(0)$ & $0.90 * *$ \\
\hline REG & 9 (87.5) & $0.97 * *$ & $3(50)$ & $0.90 * *$ & $3(50)$ & $0.83^{* *}$ & $1(0)$ & $0.95 * *$ \\
\hline $\mathrm{CP}$ & $8(75.0)$ & $0.96 * *$ & $4(100)$ & $0.97 * *$ & $4(100)$ & $0.98 * *$ & $1(0)$ & $1.00 * *$ \\
\hline LIG & $7(62.5)$ & $0.90 * *$ & 4 (100) & $0.87 * *$ & $3(50)$ & $0.81 *$ & $3(50)$ & 0.67 \\
\hline
\end{tabular}

${ }^{+} \mathrm{TDM}$, total dry matter yield; \%L, leaf percentage; LDM, leaf dry matter yield; REG, regrowth; CP, crude protein; NDF, neutral detergent fiber; IVOMD, in vitro organic matter digestibility; LIG, lignin. *** Significant by the Student $t$ test at $5 \%$ and $1 \%$ probability, respectively.

In the Urochloa ssp. AD, this SE was $100 \%$ for many traits in the two separate sites (T4 and T5). This confirms that one year should be enough for selecting the best genotypes. However, when considering the combined analyses between these two sites, the SE was $0 \%$, with coincidence of only two genotypes of the four selected among the eight evaluated (Table 2). This happened due to the low number of genotypes considered since the number of genotypes chosen at random in only two selections became biased.

The decision to reduce the time for selection will likely create concern on the part of breeders because of lack of confidence that early selection will be coincident with additional measurements. Thus, to confirm that early selection can be performed, the ranking of genotypes from the optimal number of harvests and all harvests were compared using Spearman rank correlations.

The Spearman rank correlation was high for all the traits in the evaluation trials (Table 2). Values above 0.90 were observed for the traits in the screening trial (T1), which is evidence that selection in one year and a half compared to two years should fall on the same genotypes with a selection intensity of $20 \%$. For advanced trials, the correlations were above 0.71 (\%L, T6), but extremely high values, above 0.95, were found, including 1.0 for NDF (T5) and CP (T6).

In conclusion, our results provide strong evidence that early selection is possible in Urochloa breeding programs. In screening stages that evaluate large numbers of genotypes, one year and a half is sufficient for reliable selection. Selection decisions are more critical in advanced trials, in which MAPA requests two years of evaluation under harvesting and two years for grazing evaluation before a cultivar can be registered and released for commercial use in Brazil (Jank et al. 2014). In the advanced trials, the number of genotypes is small, and the genotypes are more stable, so our results indicated that evaluation could be carried out in just one year to select the best genotypes. However, additional studies in advanced trials with more environments and genotypes should be carried out to confirm these results. Nevertheless, the results presented here considering several trials attest that adoption of early selection in breeding of tropical forages such as the genus Urochloa can significantly save time, effort, and resources without loss of reliability in releasing a cultivar.

\section{ACKNOWLEDGMENTS}

The authors thank UNIPASTO, CNPq, Fundect, and Embrapa Gado de Corte for financial support to carry out the experiments, and CAPES for granting a doctoral degree scholarship (Finance code 001).

\section{REFERENCES}

Alves GF, Figueiredo UJ, Filho ADP, Barrios SCL and Valle CB (2014)

Breeding strategies for Brachiaria spp. To improve productivity - an ongoing project. Tropical Grasslands-Forrajes Tropicales 2: 4-6.

Basso, KC, Resende RMS, Valle CB, Gonçalves MC and Lempp B (2009)
Avaliação de acessos de Brachiaria brizantha Stapf e estimativas de parâmetros genéticos para caracteres agronômicos. Acta Scientiarum Agronomy 31: 17-22.

Casler MD (1999) Repeated measures vs. repeated plantings in perennial forage grass trials: an empirical analysis of precision and accuracy. Euphytica 105: 33-2. 
Euclides VPB, Macedo MCM, Valle CB, Difante GS, Barbosa RA and Cacere ER (2009) Valor nutritivo da forragem e produção animal em pastagens de Brachiaria brizantha. Pesquisa Agropecuária Brasileira 44: 98-106.

Falconer DS and Mackay TFC (1996) Introduction to quantitative genetics. Longman Malaysia, London, 480p.

Figueiredo UJ, Nunes JAR and do Valle CB (2012) Estimation of genetic parameters and selection of Brachiaria humidicola progenies using a selection index. Crop Breeding and Applied Biotechnology 12: 237-244.

Gilmour A, Gobel B, Cullis B and Thompsom R (2009) ASReml user guide release 3.0. VSN International, Hemel Hempstead, 372p.

Hamblin J and Zimmermann MJO (1986) Breeding common bean for yield in mixtures. Plant Breeding Reviews 4: 245-272.

Jank L, Barrios SC, Valle CB, Simeão RM and Alves GF (2014) The value of improved pastures to Brazilian beef production. Crop and Pasture Science 65: 1132-1137.

Jank L, Valle CB and Resende RMS (2011) Breeding tropical forages. Crop Breeding and Applied Biotechnology 11: 27-34.

Matias FI, Barrios SCL, Valle CB, Mateus RG, Martins LB and Moro GV (2016) Estimate of genetic parameters in Brachiaria decumbens hybrids. Crop Breeding and Applied Biotechnology 16: 115-122.

Kosak M and Piepho HP (2017) What's normal anyway? Residual plots are more telling than significance tests when checking ANOVA assumptions. Journal of Agronomy and Crop Science 1: 1-13.

Kottek M, Grieser J, Beck C, Rudolf B and Rubel F (2006) World map of Köppen-Geiger climate classification updated. Meteorologische Zeitschrift 15: 259-263.
Marten GC, Shenk JS and Barton FE (1989) Near infrared reflectance spectroscopy (NIRS): Analysis of forage quality. Agriculture handbook (USA), n. 643, 110p.

Nogueira MP (2012) Rally da Pecuária faz diagnóstico de nossas pastagens. Balde Branco 1: 43-45.

Oram RN (1990) Register of Australian herbage plant cultivars. $3^{\text {rd }}$ edn. Australian Herbage Plant Registration Authority, Division of Plant Industry, Common Scientific and Industry Research Organization (CSIRO), Melbourne, 304p.

Pedrozo CÂ, Barbosa MHP, Silva FL, Resende MDV and Peternelli LA (2011) Repeatability coefficient of full-sib sugarcane families across harvests and the efficiency of early selection. Euphytica 182: 423-430.

Resende MDV (2002) Genética biométrica e estatística no melhoramento de plantas perenes. Embrapa Informação Tecnológica, Brasília, 975p.

Resende MDV and Duarte JB (2007) Precisão e controle de qualidade em experimentos de avaliação de cultivares. Pesquisa Agropecuária Tropical 37: 182-194.

Resende RMS, Jank L, Valle CB and Bonato ALV (2004) Biometrical analysis and selection of tetraploid progenies of Panicum maximum using mixed model methods. Pesquisa Agropecuária Brasileira 39: 335-34.

Silva SC and Nascimento Júnior D (2007) Avanços na pesquisa com plantas forrageiras tropicais em pastagens: características morfofisiológicas e manejo do pastejo. Revista Brasileira de Zootecnia 36: 121-138.

Souza Sobrinho F, Borges V, Lédo FJS and Kopp MM (2010) Repetibilidade de características agronômicas e número de cortes necessários para seleção de Urochloa ruziziensis. Pesquisa Agropecuária Brasileira 45: 579-584.

Valle CB, Jank L, Resende RMS (2009) O melhoramento de forrageiras tropicais no Brasil. Revista Ceres 56: 460-472. 